\title{
EVOLUCIJA POJMA STRATEGIJE IN NJEGOVO POVEZOVANJE S POLITIKO
}

Povzetek V prispevku na podlagi zgodovinskega in kritičnega pristopa različnih pomembnejših teoretikov k razvoju strategije pojasnjujemo evolucijo pojma strategije, zlasti pa, zakaj in kako je njegov pomen povezan s človekovo naravo in tudi političnim vedenjem. Spoznanja raziskave kažejo dvoje, in sicer, da se je v zgodnjem zgodovinskem obdobju strategija snovala predvsem zaradi človekovih potreb po varnosti, v sodobni strateški misli, ko je ta potreba prerasla v širše politično vprašanje družbe, pa se je razumevanje strategije vse bolj povezovalo s politiko in njenim vplivom na proces oblikovanja in uresničevanja strategije.

Ključne Strategija, taktika, politika.

besede

Abstract Based on the historical and critical approaches of various important theorists to the development of strategy, this paper aims to explain the evolution of the concept of strategy, especially why and how its meaning is related to the human nature and the political behaviour. The research has shown two things. First, that in the early historical period the strategy was designed mainly due to the human need for security, and, second, that in the modern strategic thought when these needs grew into a broader political issue of the society, the understanding of strategy was increasingly being related to the politics and its impact on the devising and implementation of a strategy.

Key words Strategy, tactics, politics. 
Uvod Koncept strategije se je skozi zgodovino izkazal za težko opredeljivega. Številni teoretiki so $\mathrm{k}$ opredelitvi strategije pristopali ozko, omejeno na vojaške zadeve, drugi, predvsem v moderni zgodovini, so pojem umeščali v širši, politični kontekst. Veliko pa je bilo tudi takih, ki so poskušali opredeliti strategijo le zato, da bi se izpostavili kritikam, kar je pojem strategije še dodatno oddaljevalo od njegove trajnejše pomenske vrednosti. Kontestacija opredeljevanja strategije je povezana z dojemanjem družbenih zakonitosti, saj je strategija proces, ki se mora nenehno prilagajati spreminjajočim se razmeram v svetu, kjer prevladujejo naključje, negotovost in dvoumnost. Clausewitz pravi, da v takem okolju načela, pravila ali celo sistemi strategij zaradi trajne zapletenosti sveta navadno vedno zatajijo (Clausewitz, 2004). Zato je proučevanje evolucije pojma strategije poseben konceptualen izziv, še posebej, ker je strategija močno prepletena z družbenimi institucijami, normami in vzorci vedenja, s politiko, ki jo usmerja, in kulturo, ki vpliva nanjo, in ker se je pojem strategije skozi zgodovino pogosto spreminjal.

S semantičnega oziroma terminološkega vidika bo proučevanje evolucije pojma strategije bolj oprto na onomaziološki kot pa na semaziološki pristop ${ }^{1}$, ki pojasnjuje zgodovino rabe pojma strategija. Onomaziološki pristop nam bo omogočil retrospektivni pogled $\mathrm{V}$ strategijo; na podlagi njega bomo lahko natančneje ugotavljali, kako so strategi oziroma pisci o vodenju vojn razmišljali o strategiji v preteklosti, ne glede na to, ali so pri tem sploh omenjali strategijo. S tem pristopom bomo lahko bolje razumeli tudi, zakaj je toliko polemik o rabi pojma strategije in zakaj se je pojem skozi čas tako pogosto spreminjal.

Čeprav bomo v prispevku izhajali iz zgodovinske metode razlage pojma strategije in njegovih spremljajočih značilnosti skozi čas, bo pozornost proučevanja usmerjena predvsem na povezanost strategije s politiko. V prispevku razumemo pojma strategije in politike v ontološkem smislu, kot koncepta. Tako lahko kompleksne in dimenzionirane lastnosti poenostavimo oziroma posplošimo ter jih predstavimo čim bolj smiselno in razumljivo. Cilj prispevka je na podlagi temeljnih del ter razmišljanj in kritik različnih avtorjev, ki so s svojimi deli prispevali k razvoju in uveljavljanju strategije v teoriji in praksi, izpostaviti evolucijske mejnike razumevanja strategije, ki so pripeljali do njene povezanosti s politiko.

Namen tega prispevka torej ni oblikovanje doktrine oziroma sistema teorij $\mathrm{s}$ področja strategije, temveč skozi zgodovinski pregled temeljne literature prikazati različna razmišljanja številnih mislecev, ki so vplivala na potek razvoja pojma strategije in njegove povezanosti s politiko. Oblikovalcem strategij in politik lahko ta razmišljanja sicer pomagajo pri dojemanju razsežnosti strategije, iskanju idej in napotkov iz zgodovinskih izkušenj, ne morejo pa zagotoviti pravih odgovorov na izzive, s katerimi se spoprijemajo. Kljub temu je zgodovina tista, ki jo je pri

Pri onomaziološkem pristopu izhajamo iz denotata oziroma predmetnosti in se sprašujemo, kako, kdo/kaj poimenuje. Pri semaziološkem pristopu izhajamo iz nabora črk oziroma glasov, ki nam predstavijo izraz oziroma izrazno podobo nekega leksema. Pri semaziološkem pristopu torej izhajamo iz izraza in se sprašujemo, kaj nam izraz pomeni. 
teoretičnem in praktičnem razumevanju strategije treba poznati in upoštevati, saj lahko v mnogočem prav ta spoznanja dajo koristen namig oblikovalcem strategij pri spoprijemanju s strateškimi izzivi prihodnosti in sprejemanju, kot pravi Gray (2010, str. 8), racionalnih odločitev.

\section{EVOLUCIJA POJMA STRATEGIJA: RAZLIKOVANJE MED STRATEGIJO IN TAKTIKO}

Etimologi pripisujejo izvor pojma »strategija« starodavni grški besedi strategia ali strategiké ( $\sigma \tau \rho \alpha \tau \eta \gamma i ́ \alpha)$, ki se nanaša na vodenje vojske oziroma na veščino vojskovodij (Liddell in Scott, 1940, str. 1368; Žabkar, 2003, str. 182). V antiki je bil uporabljen kot veščina ali spretnost generalov (strategós) - general je bil tisti, ki je izvajal strategijo. V 6. stoletju, v času cesarja Justinijana I. (527-565), so Bizantinci začeli razlikovali med taktiko kot veščino vodenja enot in sodelovanja teh v boju, in strategijo kot veščino o pripravah in vodenju vojne ter uporabi sile, ki je vojskovodji omogočila obrambo njegovega ozemlja in premoč nad sovražnikom. V tej hierarhični zasnovi je bila taktika sicer povezana s strategijo, vendar po obsegu in namenu njej podrejena. Čeprav sta se strategija in taktika med seboj razlikovali, sta obe ohranjali značilnosti vojaške teorije in prakse (Anonymous Byzantine, 6. stol., 1985, str. 10-135; Heuser, 2010, str. 4).

Heuserjeva ugotavlja, da je velika verjetnost, da pojem strategija izhaja iz zgodnejših izgubljenih del Eneja (z vzdevkom Taktik), grškega pisca o vojni kot veščini iz 4. stoletja pr. n. št., Marka Porcija Kantona iz 1. oziroma 2. stol. pr. n. št., najstarejšega latinskega pisca, ki se je ukvarjal z vojaškimi vprašanji, in Seksta Julija Frontina, rimskega vojnega in tehničnega pisca iz 1. stoletja (Heuser, 2010, str. 4). Frontin je na primer naslov svojega dela, sicer napisanega v latinici, poimenoval z grško besedo Strategemata (ali Stratagema), ki v grškem prevodu pomeni zvijača, ukana v vojni oziroma mojstrstvo, da se sovražnik napelje v zmotno presojo in ravnanje (glej tudi Žabkar, 2003, str. 182). Nobena izmed teh dveh besed grškega porekla takrat ni imela prave latinske prevodne ustreznice, kar je lahko tudi posledica nesistematičnega razlikovanja med strategijo in taktiko, izhajajočega iz grških spisov (Heuser, 2010, str. 4). Mavricij (539-602). Vzhodnorimski (bizantinski) cesar naj bi po ugotovitvah nekaterih zgodovinarjev spisal priročnik o bizantinski vojaški strategiji, poznan kot Strategikón, ki se ukvarja predvsem s tehničnimi vidiki vodenja vojne. Osnovna zamisel Strategikóna je po ugotovitvah Lubija specifična defenzivna strategija (Lubi, 2008, str. 37), kar je odraz dejstva, da je bil Bizanc v tistem času močno izpostavljen vojaškemu pritisku različnih barbarskih plemen. V 2. stoletju je podobno delo objavil grški vojaški pisec Aelian Taktik (Aelianus Tacticus), ki je živel v Rimu, in sicer z naslovom Taktiké Theoría.

Bizantinski cesar Leon VI. Modri (886-912) se je pri ustvarjanju razprave o vojaških operacijah z naslovom Taktiká (Leon, 900/2010) v večji meri opiral na spoznanja Aeliana Taktika, medtem ko je pojma strategija in taktika uporabil v podobnem medsebojnem (hierarhičnem) odnosu, kot so ga razumeli Bizantinci v 6. stoletju. 
Leonovo delo je med drugim pomembno tudi z vidika širjenja pomena strategije na zahod. Johann VII., nemški grof Nassau-Siegen (1561-1623) je pri pisanju knjige o vojni (angl. Book of War) črpal znanje iz obeh bizantinskih del, Mavricijevega Strategikóna in Leonove Taktike. Heuserjeva navaja, da se je njegovo razmišljanje o vodenju vojne od omenjenih bizantinskih del razlikovalo predvsem v tem, da ni sprejemal grškega pojmovanja strategije kot veščine vojskovodij, temveč je le temeljilo na rabi pojma taktika (Heuser, 2010, str. 4). Johann VII. je pri tem le uporabil Leonov analitični okvir, medtem ko pojem strategija v tistem času še ni bil integriran v zahodne jezike.

Številni zahodnoevropski avtorji, ki so delovali pred francosko revolucijo, niso pisali niti o strategiji niti o taktiki, temveč o vojaškem področju kot celoti. V glavnem so le prevajali tradicionalne rimske avtorje, kot je to bil na primer Vegecij ${ }^{2}$ iz 4. stoletja, ki je za svoja dela uporabil naslov Razprava o vojaški veščini (Epitoma rei militaris). Pozneje, v 16. in 17. stoletju, v obdobju, ki ga lahko obravnavamo tudi kot zarodek sodobne vojaške znanosti, je miselni preboj dosegel italijanski politolog in filozof Machiavelli z delom O veščini vojskovanja (Libro dell'arte della guerra iz leta 1521). Iz tega obdobja je znan tudi Puységur, ki je izdal vojaška navodila (Avec des Instructions militaires iz leta 1690) (Žabkar, 2003, str. 12; Heuser, 2010, str. 5).

Razlikovanje med strategijo in taktiko se je na zahodu uveljavilo šele okrog leta 1700, ko je bil termin taktika preveden v francoski in nemški jezik. K temu je v tistem času najbolj pripomogel francoski maršal Jacques Antoine Hippolyte de Guibert (1743-1791) s svojim delom Splošni esej o taktiki. V njem je opredelil nadrejene in podrejene ravni vodenja vojne, ločil je taktiko in višjo oziroma veliko taktiko (angl. grand tactics), ko je razpravljal o ciljih vojne, konfiguraciji oboroženih sil v povezavi s političnimi cilji in o drugih dimenzijah, ki jih danes umeščamo $\mathrm{v}$ strategijo. Heuserjeva ugotavlja, da Guibert v svojem delu besede strategija sploh ni omenjal, čeprav je pisal o tem, kar danes pojmujemo kot strategija in taktika (Heuser, 2010, str. 5). Osredotočal se je predvsem na razmerje med naravo družbe, njenimi notranjimi vrednotami in cilji zunanje politike (tako imenovano splošno strategijo, ki izhaja iz teh vrednot in ciljev), oboroženimi silami ter načini njihove uporabe do bojnih taktik.

Kmalu po izdaji Guibertovega dela se je bizantinska raba pojmov strategija in taktika, ki je še danes aktualna, uveljavila na zahodu. Dodaten impulz razvoju vojaške teorije in terminologije nasploh je prispeval tudi razvoj tiska, ki je vse od 17. stoletja pomembno pripomogel k tiskanju knjig z vojaško tematiko. Francoz PaulGédéon Joly de Maizeroy (1719-1780) je na primer prevedel Leonovo knjigo o

\footnotetext{
Vegecijevo delo Razprava o vojaški veščini velja za nekritično in časovno nedoločljivo kompilacijo starejših rimskih piscev, kot sta bila Kanton in Fortin, in zakonskih predpisov cesarjev Avgusta, Trajana in Hadrijana. Njegova razprava je postala ena izmed najpomembnejših klasičnih vojaškoteoretičnih študij. Njegova priljubljenost je posledica splošnih vojaških pravil, v katera je Vegecij poskušal strniti celotno veščino vojskovanja. Od 16. stoletja naprej je Vegecijev vpliv na splošno upadel, čeprav je še bil močno prisoten v delih Machiavellija, Montecuccolija in drugih (Lubi, 2008, str. 25-26).
} 
taktiki v francoski jezik, vendar je pri prevodu Leonovega pojmovanja strategije še vedno omahoval in raje uporabil v prevodu »veščino vojskovodij«, medtem ko je besedo »stratégique« omenil v svojih komentarjih. S tem prevodom sta se na zahodu prvič uporabila oba pojma $\mathrm{v}$ hierarhičnem odnosu, pri čemer je strategija pomenila višjo, taktika pa nižjo raven vojskovanja. Leta 1777 je Johann von Bourscheid na Dunaju to isto bizantinsko delo še natančneje prevedel v nemški jezik ter ga poimenoval Strategija in taktika cesarja Leona Modrega. Od takrat sta se oba pojma v bizantinskem smislu razširila in uveljavila tudi na zahodu.

\section{STRATEGIJA MED POLITIKO IN TAKTIKO}

Ne glede na to, ali so pisci v svojih delih od antike naprej uporabili termin strategija ali ne, so poskušali zasnovati strategijo na podlagi praktičnih izkušenj (strategija kot dejavnost ali veščina) ali teoretičnih razmišljanj (strategija kot znanstvena disciplina), preden so jo uporabili v vojni. Podobno so se razlikovali tudi avtorji del o vojni glede na to, ali so razpravljali o vojni kot veščini ali znanosti. Strokovni in znanstveni diskurz, ki se od leta 1800 prekriva z vprašanjem, ali strategija zadeva samo teoretični vidik ali tudi praktično uporabo, po najavah Heuserjeve še do danes ni dobil poenotenega epiloga (Heuser, 2010, str. 5-6). To vprašanje se prvič pojavi v spisih nadvojvode Karla (1771-1847), habsburškega poveljnika v vojnah proti Napoleonu, ki je leta 1806 opredelil strategijo kot znanost o vojni. S strategijo se zasnuje načrt, omeji in določi razvoj vojaških operacij - je posebna znanost vrhovnega poveljnika. Prav nasprotno pa opredeli taktiko kot veščino vojne (angl. art of war), s katero se poučujejo načini izvajanja strateških načrtov - je potrebna spretnost vsakega vojaškega poveljnika enote.

Najpomembnejši med omenjenimi vojaškimi teoretiki na prelomu 18. in 19. stoletja je prav gotovo pruski teoretik Carl von Clausewitz (1780-1831), ki je utemeljil sodobno teorijo vojne (Žabkar, 2003, str. 17). V svojem opusu O vojni je na široko odprl vrata opredeljevanju strategije na višji in splošnejši konceptualni ravni. Čeprav je v opredelitvi strategije ohranil njen izvorni vojaški značaj, je njegova opredelitev strategije kot »uporabe spopada za smoter vojne« (Clausewitz, 2004, str. 103) pripeljala do povezave strategije in politike kot tudi vzpostavitve jasne hierarhije med tremi pojmi: politika - strategija - taktika. Clausewitz je opredelil namen vojne kot »akt sile, da bi nasprotnika primorali k izpolnitvi naše volje« (prav tam, str. 18). Ta akt, ki izhaja iz politike kot gonilne sile vojne, pa ni samo politični akt, temveč pravi politični instrument oziroma, kot je trdil Clausewitz: »Vojna je samo nadaljevanje politike $\mathrm{z}$ drugimi sredstvi« (Clausewitz, 2004, str. 103). Tako je Clausewitz strategijo postavil na najvišjo raven, pozneje znano pod nazivom velika, splošna strategija (angl. grand strategy) ${ }^{3}$. Namen velike strategije je bil vzpostaviti

\footnotetext{
Pomen Clausewitzeve vojaškoteoretične ustvarjalnosti je tudi v njegovi ideji o delitvi veščine vojskovanja na razmeroma samostojna področja. Nujnost te delitve teoretično pojasnjuje s tezo, da obstajajo v okviru bojevanja posamezne celote (boji), iz česar izpeljuje sklep o razmejitvi veščine vojskovanja na taktiko kot znanost o uporabi oboroženih sil v boju in strategijo kot znanost o uporabi bojev za dosego cilja vojne (glej tudi Lubi, 2008, str. 7).
} 
povezavo med politiko in strategijo na strateški ravni. Clausewitzeva opredelitev strategije kot političnega akta je pokazala, da so bili ne glede na raven analize vsi koncepti strategije povezani z določenim političnim ciljem. Taka, splošnejša, konceptualna opredelitev strategije je omogočila, da je bilo vanjo mogoče vključiti tako vsebine vojaške taktike in velike strategije kot tudi drugih področnih strategij (na primer diplomacije in ekonomije). Tako se je utrla pot oblikovanju tipologije strategij.

Ta sicer še vedno precej ozka opredelitev strategije Clausewitza in njegovega sodobnika Henrija Jominija ${ }^{4}$ s poudarjanjem njenega vojaškega značaja je obveljala vse do konca 19. stoletja. Francoski maršal Marmont je na primer leta 1845 opredelil strategijo kot splošen premik, ki je izveden zunaj vidnega polja nasprotnika in pred bitko, taktiko pa kot znanost o uporabi manevra in veščino o vodenju vojaških enot na bojišču (Marmont, 1865, str. 8, 14). Francoski pomorski častnik Louis-Édouard, grof Bouët-Willaumez, je leta 1853 opredelil strategijo kot veščino določanja odločilnih točk vojskovališča ter splošnih smeri, po katerih bi se morala premakniti vojska za dosego teh točk. Te nedomiselne opredelitve strategije so se po ugotovitvah Heuserjeve ponavljale še v 20. stoletju, zlasti zunaj Francije, kjer sta se pojma taktika in strategija bolj uveljavila šele po porazu Francije, ki ji ga je prizadejala Prusija v letih 1870/71 (Heuser, 2010, str. 7). Helmuth von Moltke starejši, pruski maršal (1800-1891), je na primer videl bistvo strategije v pripravah, potrebnih za sočasen premik vojaških enot na bojišče. Izjavil je, da je strategija več kot znanost, je sistem možnosti (metod), ki se v praksi po navadi ne skladajo s splošnimi, naučenimi načeli vojne. Strategija je znanje, preneseno v resnično življenje, razvoj izvirnih zamisli, ki jih zahtevajo nenehno spreminjajoči se dogodki, in veščina delovanja pod pritiskom najtežjih okoliščin (Foch, 1920, str. 18; Hughes, 1993, viii-ix, 124) ${ }^{5}$. Vsaka situacija namreč zahteva specifično razlago in rešitve, pri čemer se izurjenost in znanje kombinirata $\mathrm{z}$ jasnostjo stališč in drznostjo. Njegov ruski sodobnik general Mikhail Ivanovič Dragomirov je zavračal koncept vojaške znanosti in bolj zagovarjal koncept teorije vojne (Foch, 1920, str. 8) ${ }^{6}$. Pojavljale so se tudi druge, bolj kot ne tehnične opredelitve strategije. Eno takih je podal Clausewitzev sodobnik Wilhelm von Willisen, in sicer, da je strategija doktrina potreb (nem. Bedürftigkeit), taktika pa pomeni doktrino bojevanja (nem. Schlagfähigkeit) (Willisen, 1840, str.

\footnotetext{
4 Jominijevi pogledi na razvoj sodobne strateške misli so med drugim pomembno prispevali $k$ razjasnitvi temeljnih vprašanj vojaške znanosti ter $k$ opredelitvi vloge strategije v vojskovodstvu. V njegovem najpomembnejšem teoretičnem delu Pregled veščine vojskovanja (Precis de l'art de la guerra) iz leta 1836 se najbolj in najceloviteje posveča opredelitvi temeljnih (strateških) načel vojskovanja, in sicer koncentraciji sil, spoštovanju zadanega cilja, pregonu sovražnika, ofenzivnosti, zavarovanju sil, presenečenju in ekonomiziranju sil (Lubi, 2008, str. 69-71). Pri tem je opredelil strategijo kot veščino vojskovanja, ki se izvaja na podlagi načrta ter obsega celotno vojskovališče, na katerem poteka vojna (Jomini, 2007, str. 51).

5 Moltke je sicer priznaval vpliv politike na začetek in konec vojne in trdil, da lahko politični cilji in okoliščine zmeraj spremenijo strategijo, vendar je hkrati zahteval, da mora imeti poveljnik pri izvajanju vojaških operacij povsem proste roke. Od tod tudi njegova trditev, da strategija ni odvisna od politike in da je ne glede na objektivne politične razmere pri doseganju daljnosežnih vojnih načrtov in velikih uspehov mogoče in treba tvegati. Za Moltkeja je bil prvi boj preizkus vseh strateških presoj in izračunov (Lubi, 2008, str. 84).

${ }^{6}$ Foch je v svojem delu Načela vojne (angl. The Principles of War) ugotovil, da veščina vojne kot vsaka druga veščina temelji na teoriji in načelih, drugače sploh ne bi mogla postati veščina (Foch, 1920, str. 9).
} 
40). Britanci sir Hamley, general Maurice in polkovnik Henderson ${ }^{7}$ so na prehodu iz 19. v 20. stoletje strategijo razlagali kot veščino usmerjanja vojaških enot za doseganje ciljev kampanje. Pri tem je vojskovališče predstavljalo domeno strategije, bojišče pa domeno taktike (glej tudi Heuser, 2010, str. 7). Francoski general Bonnal, predavatelj na vojaški šoli Ecole de Guerre v letih 1892/93, je študentom predaval, da je strategija veščina zamišljanja, taktika pa znanost o njeni izvedbi.

Tehnične opredelitve strategije niso vključevale političnih smernic, ki so pravzaprav podlaga za njeno oblikovanje. Za tako razumevanje strategije je bilo treba koncept bistveno razširiti. Britanski vojaški zgodovinar Henry Spenser Wilkinson je leta $1894 \mathrm{v}$ razpravi o pomorski operaciji podal naslednjo opredelitev: »Politika je sistem ukrepov, usmerjenih $\mathrm{v}$ doseganje cilja ali namena. Cilji morajo izhajati iz nacionalnih vrednot in prizadevanj, da bi vlada lahko imela ustrezno podporo pri njihovem uresničevanju. Prav tako se morajo tudi razpoložljiva sredstva skladati s postavljenimi cilji« (Wilkinson, 1894, str. 21). Deset let pozneje je podpolkovnik Walter James ${ }^{8}$, čeprav je še vedno ostajal na ozki opredelitvi strategije in taktike, razmišljal tudi o političnih ciljih vojskovanja: »Na strategijo zelo vpliva moralni dejavnik. Pri odločanju med dvema različnima ciljema, izmed katerih eden prispeva $\mathrm{k}$ povsem političnim, drugi pa $\mathrm{k}$ čisto vojaškim rezultatom, dobimo veliko večjo korist, če izberemo prvi cilj, ker ima večji učinek na cilj vojne« (James, 1908, str. $17 b)$.

Opazimo lahko, da se je ločnica med politiko in strategijo, še posebej veliko strategijo, na prehodu iz 19. v 20. stoletje vse bolj izgubljala. Po prvi svetovni vojni je Johannes Kromayer nadaljeval razvoj pojmovanja strategije; trdil je, da sta bili Clausewitzeva (politika določa izključno končne cilje vojne na začetku vojne) in Delbrückova zamisel, ki je k temu pripisoval še pomen velikega boja, pomanjkljivi. Kromayer navaja, da se morajo cilji vojne, politika in v tem okviru tudi strategija skozi celotno vojno vseskozi spreminjati in prilagajati v smislu zasledovanja uspešnega ali neuspešnega poteka operacij ${ }^{9}$ (Kromayer, 1925, str. 401). Sredi obdobja hladne vojne je André Beaufre to razmišljanje še poglobil. Clausewitzevo opredelitev strategije je interpretiral kot veščino dialektike sile oziroma veščino dialektike dveh nasprotujočih si volj, ki uporabita silo za reševanje sporov, zaradi katerih je prišlo do

\footnotetext{
Med njimi Henderson na primer opredeljuje strategijo kot veščino, s katero je nasprotnika mogoče zaplesti v boj, taktiko pa kot izbiro metode, s katero namerava poveljnik premagati sovražnika v boju (Henderson, 1910 , str. 39).

8 James je veščino vojne delil na dva dela - strategijo in taktiko. Strategija se ukvarja z vojaškimi dejavniki, ki določajo izbiro med ofenzivno in defenzivno doktrino bojevanja, izbiro območja bojevališča, cilje, ki jih mora vojska doseči, in načrt kampanje ali splošno idejo, s katero se usmerja vodenje operacij. V splošnem smislu se strategija ukvarja s premikom vojaških enot, še preden pridejo v stik z nasprotnikom, taktika pa se ukvarja $z$ vodenjem enot $v$ boju. Taktična zmaga lahko pomeni uvod $v$ strateški uspeh kot tudi kulminacijo uspešne strategije (James, 1908, str. 18).

9 Končnega cilja vojne po spoznanjih Kromayerja ni mogoče ugotoviti ob njenem začetku, še posebej ne, če gre za države s podobno vojaško silo in države z velikim obsegom zmogljivosti in virov, ki povrh vsega lahko računajo tudi na pomoč svojih zaveznikov, ki sprva v konflikt sploh niso bili vpleteni. V takšnih primerih končne cilje vojne v bistvu določajo uspehi, doseženi v vojni, in se lahko močno razlikujejo od začetnih do končnih kampanj oziroma poraza nasprotnika (Kromayer, 1925, str. 401-402).
} 
konfrontacije (Beaufre, 1968, str. 20). Ameriška vojaška zgodovinarja Williamson Murray in Mark Grimsley sta ugotavljala podobno in opredelila strategijo kot proces stalnega prilagajanja spremenjenim pogojem in okoliščinam v svetu, v katerem prevladujejo priložnosti, negotovosti in nejasnosti (Murray in Grimsley, 1994, str. 1). Podobno mišljenje ima tudi britanski vojaški zgodovinar Hew Strachan, ki strategijo v vojni opredeljuje kot proces stalnega prilagajanja glede na dejanja nasprotnika ter stalnega preverjanja in oblikovanja novih politik, pri katerih sodelujejo tako politični in vojaški voditelji kot tudi drugi strokovnjaki (Strachan, 2006, str. 59-68) ${ }^{10}$.

Najuglednejši zagovornik povezovanja politike in vojaških nalog je bil sredi prejšnjega stoletja sir Basil Henry Liddell Hart. Leta 1941 je opredelil strategijo kot »veščino distribucije in uporabe vojaških sredstev za dosego političnih ciljev« (Liddell Hart, 1967, str. 321). Prednost take opredelitve strategije je bila v njeni širini, ki jo je Richard Betts kritično ovrednotil v smislu, da je tako široka raba pojma strategije postala sopomenka za zunanjo politiko (Betts, 2001/2, str. 23).

Široko dojemanje koncepta strategije je bilo prepoznano tudi v razpravah med že omenjenim francoskim generalom Andréjem Beaufrejem in francoskim sociologom Raymondom Aronom. Aron je celo predlagal združitev pojmov politike in strategije ter oblikovanje nove besedne tvorbe oziroma vpeljavo neologizma, poimenovanega prakseologija (angl. praxeology). Beaufre temu združevanju ni bil naklonjen, zato je diferenciacijo med tema pojmoma gradil na totalni strategiji, ki je pravzaprav ekvivalent britanskemu pojmu velika strategija ${ }^{11}$. Beaufre je namreč zagovarjal,

\footnotetext{
${ }^{10}$ Clausewitzeva razprava o tem, da je vojna instrument politike, poudarja pomen političnega vidika v vojni, $k i$ predstavlja najvišje stališč za vodenje vojne, v kateri nobeden od glavnih načrtov, ki so za vojno potrebni, ne more biti narejen brez uvidov v politična razmerja. Politika je v takem kontekstu pravilna, če dosega svoj cilj, kar ugodno učinkuje tudi na vojno. Kjer pa se to učinkovanje oddaljuje od cilja, je treba izvor iskati le v napačni politiki (Clausewitz, 2004, str. 288-290). Z drugimi besedami: politika mora prepoznati in biti skladna z dejansko naravo vojne. Če si politika ob razpoložljivih vojnih sredstvih in ukrepih obeta napačno učinkovanje, ki ne ustreza njihovi naravi, ima lahko s svojimi odločitvami škodljiv vpliv na vojno. Strachan pravi, da je politika, ki uvidi vojno le kot instrument, ne da bi pri tem razumela naravo instrumenta, slaba politika. V tem smislu razume strategijo kot produkt dialoga med politiki in vojaki; njeno bistvo je v uskladitvi obeh subjektov, in ne podrejanje ene drugi (Strachan, 2006, str. 67-68). Strategija v vojni namreč ni samo vprašanje splošne politične usmeritve, temveč in predvsem koherentnosti med politiko, vojaškimi zmogljivostmi in dogodki na kraju samem.

${ }^{\prime \prime}$ Čeprav je strategija samo ena glede na cilj in metodo, se mora pri izvajanju nujno deliti na specializirane strategije, ki veljajo za oziroma usmerjajo posamezna področja. Vsaka strategija mora namreč skrbeti za materialna sredstva, katerih lastnosti se od področja do področja razlikujejo (pomorska se na primer vedno razlikuje od kopenske strategije in podobno). Tako Beaufre pride do piramide posebnih in medsebojno odvisnih strategij, ki jih je treba natančno opredeliti, da bi se lahko čim optimalneje kombinirale možnosti pri uresničevanju skupnega cilja. Razlikuje med totalno strategijo (neposredno podrejena vladi oziroma politiki, njena naloga je oblikovanje zamisli o vodenju totalne vojne ter določanje posameznih nalog v kombinaciji z različnimi splošnimi, področnimi strategijami v političnem, gospodarskem, diplomatskem in vojnem pogledu), splošno področno strategijo (za vsako področje (vojaško, politično, gospodarsko in diplomatsko) obstaja področna strategija, ki ima funkcijo določanja in kombiniranja nalog, ki se izvajajo znotraj posameznega področja) in operativno strategijo (podrejena je področni strategiji in predstavlja vez med zamislijo in izvedbo, med tem, kar se želi izvesti, in tistim, kar je mogoče izvesti glede na tehnične omejitve) (Beaufre,1968, str. 30-32). Beaufre operativno strategijo prepoznava na vsakem področju. Njeno bistvo ni samo v uskladitvi ciljev področne strategije z zmožnostmi taktike in tehnike tega področja, temveč tudi, da usmerja njuno evolucijo, prilagojeno potrebam področne strategije. V klasični kopenski strategiji ravno na ravni operativne strategije prihajajo do izraza logistični in taktični dejavniki (obseg sil glede na prostor, strateška in taktična premičnost, ofenzivna in defenzivna zmogljivost), od katerih so odvisne vse vojaške sposobnosti strategije (Beaufre,1968, str. 32).
} 
da so vse vojne totalne, ker potekajo na vseh družbenih področjih od političnega, gospodarskega, vojaškega do kulturnega in drugih (Beaufre, 1968, str. 30-31, Heuser, 2010, str. 8). Tak pogled pa po drugi strani privede do izrazite terminološke zmede zaradi drugačnega pojmovanja in rabe izraza totalna vojna v praksi ${ }^{12}$.

Čeprav seAronov predlog pojma prakseologija ni uveljavil, se je razširilo razumevanje povezovanja med strategijo in prakso. Ameriški sodobnik Bernard Brodie je sredi obdobja hladne vojne zapisal, da mora biti strateško razmišljanje oziroma teorija strategije pragmatična - teorija za ukrepanje. Strategijo je razumel predvsem kot odgovor na vprašanje kako - v smislu praktičnega vodiča za učinkovito uresničevanje določenih ciljev (Brodie, 1973, str. 45-4532). Na podlagi Brodiejevih spoznanj je Gray razvil idejo teorije strategije do te mere, da je uporabna pri izobraževanju strategov in razvijanju njihovih zamisli o načrtovanju in uresničevanju strategije (Gray, 2010).

Z uvedbo koncepta velika strategija med drugo svetovno vojno, ki je v marsičem zelo podoben splošni nacionalni politiki na področju zunanjih in vojaških zadev, so se odprle nove, kompleksnejše različice opredelitve strategij. Združeni štab oboroženih sil ZDA je kmalu po koncu druge svetovne vojne izdal slovar vojaških pojmov, v katerem je leta 1950 izpeljal široko opredelitev strategije, in sicer kot »veščino in znanost razvijanja in uporabe političnih, gospodarskih in psiholoških moči države ter njenih oboroženih sil v miru in vojni za zagotovitev maksimalne podpore politiki pri povečanju verjetnosti in pomena zmage ter zmanjšanja možnosti za poraz« (Dictionary of United States Military Terms, 1950, str. 83).

Britanski politolog Robert Neild je leta 1990 opredelil strategijo še širše, in sicer kot uresničevanje političnih ciljev z uporabo ali posedovanjem vojaških sredstev. Brez političnih ciljev je vojna nesmiselno uničevanje, posedovanje vojaških sredstev $\mathrm{v}$ miru pa nesmiselna potrata časa in denarja. Določitev in specifikacija političnih ciljev je prva naloga države. Vojaška sredstva, ki temu sledijo, morajo biti izbrana in prilagojena tako, da ustrezajo političnim ciljem (Neild, 1990, str. 1).

Vez med politiko na najvišji ravni in uporabo vojaške sile kot njenega orodja, ki jo je zasnoval Clausewitz, čeprav še ne popolnoma vtkal v pojem strategije, je, kot smo ugotovili, postopoma postala stvar splošnega konsenza. Kljub temu ostaja še dovolj

\footnotetext{
12 Förster in Gessler na primer idealni tip totalne vojne razlagata povsem drugače kot Beaufre, skozi štiri elemente: (1) cilje totalne vojne (brezpogojna predaja, podjarmljenje sovražne države ali naroda, načelo uničenja), (2) metode totalne vojne (neupoštevanje oziroma kršitev mednarodnega prava in skupnih moralnih načel, nepremišljena uporaba vseh vojaških sredstev proti sovražniku), (3) totalna mobilizacija (uporaba vseh sredstev države, družbe in gospodarstva za dosego končnega cilja vojne) in (4) totalni nadzor (centralizirana organizacija in namensko vodenje vseh vidikov javnega in zasebnega življenja v kontekstu vojskovanja) (Förster in Gessler, 2005, str. 56). V vseh štirih elementih implicitno prihaja do nejasnih ločnic med vojaki in civilnim prebivalstvom; civilno prebivalstvo v totalni vojni postane glavna opora vojaškim naporom kot tudi cilj vojaškega nasilja. Kombinacija predstavljenih elementov sicer omogoča razlikovanje totalne vojne od drugih oblik vojskovanja, ki pa se v praksi glede na to, da je zasnovana kot teoretični model, niti skozi posamezni element niti kot kombinacija elementov ne more v popolnosti materializirati.
} 
prostora za nadaljnje izpopolnjevanje strategije kot koncepta, ki lahko, kot pravi Heuserjeva, prispeva k odkrivanju njegovih nadaljnjih razsežnosti (Heuser, 2010, str. 9).

\section{STRATEGIJA IN POLITIKA}

Politična vloga strategije, tudi v vojni, se je kljub zadržkom vojaških poveljnikov do vmešavanja politike $\mathrm{v}$ vodenje vojne in do zagovarjanja ostre delitve $\operatorname{vlog}^{13}$, postopoma uveljavila, čeprav so stališča političnih in vojaških voditeljev do delitve vlog med politiko in vojsko še danes neenotna. Ta tako imenovani tehnični vidik opredeljevanja strategije, ki hkrati priznava tudi politične cilje vojskovanja, je mogoče zaznati v opredelitvi strategije ameriške vojske še leta 1989 (Heuser, 2010, str. 15). Konec 20. stoletja je Gray opredelil strategijo, ki ima univerzalnejšo prepoznavanje, in sicer kot uporabo vojaške moči za doseganje političnih ciljev oziroma natančneje kot teorijo in prakso uporabe ali grožnjo uporabe organizirane sile za politične namene (Gray, 1999, str. 17). Pozneje je Michael Handel podal še odločnejšo opredelitev, ki pravi, da je strategija razvoj in uporaba vseh virov v vojni in miru v podporo nacionalnim politikam pri zagotavljanju zmage (Handel, 2003, str. 36). Pri obeh ameriških opredelitvah opazimo veliko širše razumevanje strategije in vključujeta zvezo med politiko in vojno kot njenim instrumentom.

Koncept strategije je, kar je razvidno tudi iz njegove evolucije, težko opredeliti. Poskusi številnih teoretikov so se pri tem končali ob številnih kritikah. Zelo poznana že omenjena Liddell-Hartova opredelitev strategije kot veščine distribucije in uporabe vojaških sredstev za dosego političnih ciljev (Liddel Hart, 1967, str. 321) je na primer omejujoča v svoji opredelitvi, ker se nanaša zgolj na vojaške zadeve. Strategija v praksi namreč zajame veliko več družbenih področij, ki jih povrh vsega precej široko obravnava. Ozke opredelitve po mnenju Murraya in Grimsleyja oddaljujejo razumevanje strategije kot procesa (Murray in Grimsley, 1994, str. 1). V svetu, v katerem dejavnosti, namere in cilji drugih udeležencev ostajajo zasenčeni in neprepoznavni, te zapolnita modrost in intuicija najbolj premetenega oblikovalca politik. Clausewitz poudarja, da so v takem okolju načela, pravila in celo sistemi, ki jih zajame strategija, zmeraj pomanjkljivi, razvrednoteni z neomejeno kompleksnostjo sveta (Clausewitz, 2004, str. 134).

Čeprav ne obstaja enotna opredelitev strategije, je v 21. stoletju mogoče prepoznati premik k enotnejšemu razumevanju njenega izraza. Ta je še posebej osvetljen skozi vidik funkcionalnosti, pri čemer strategija predstavlja premostitveno funkcijo, ki

\footnotetext{
${ }^{13}$ Lassau je bil na začetku 19. stoletja eden izmed ostrih zagovornikov razmejitve vlog politike in vojske v vojni oziroma omejevanju politike pri vmešavanju v vodenje vojne. Vloga politike v vojni je po njegovih trditvah samo ta, da določi trenutek, ko se mir prevesi v vojno, čeprav je dopuščal možnost, da politika države (opomba avtorja: ideologija) pri odločanju o vojni vpliva tudi na njen obrambni ali napadalni značaj (Lassau, 1815, str. 7). Njegovo mišljenje je vplivalo na ustanovitev pruskega kroga tistih, ki so nasprotovali vmešavanju političnih odločevalcev v (vojaško) vodenje vojne. Med njimi je bil tudi Moltke, ki je ostro nasprotoval takratnemu pruskemu kanclerju Bismarcku in njegovemu vmešavanju v vojne za združitev Nemčije sredi 19. stoletja.
} 
služi namenski povezavi sredstev države z njenimi političnimi cilji oziroma njeno politiko. V metaforičnem smislu strategija zagotavlja storitev, ki omogoča, da lahko država svojo vojaško moč uporabi tako, da realizira politične cilje. V bistvu je treba strategijo razumeti v sodobnem smislu kot povezovalno in organizacijsko funkcijo, ki omogoča politiki z inteligentno uporabo svojih sredstev uresničevanje zastavljenih ciljev.

\section{RAZPRAVA}

1. Preučevanje strategije je večinoma povezano s preučevanjem načrtov in ukrepov zgodovinsko znanih (vojaških) strategov in političnih voditeljev, ki so s svojimi strateškimi dejanji nemalokrat premaknili smer zgodovine. V tem pogledu je strategija zelo pomembna zadeva, ki jo je treba nenehno proučevati in kritično presojati. Pri tem pa ne smemo ločiti strategije od strategov oziroma od tistih, ki jo oblikujejo in izvajajo v različnih oblikah. Strategi kot predstavniki strategij so kognicijski produkti svojega časa, kulture, družbe in vlade, torej interaktivni produkti spoznanj, ki so jih oblikovale te strukture. Proučevanje strategije je torej nepopolno brez študije strategov, ki imajo po Dolmanu enak, če ne celo prevladujoč vpliv na razvoj strategije skozi zgodovino (Dolman, 2016, str. 22-23). To nam pomaga razložiti, zakaj se prevladujoči pogledi na uspešno strategijo s časom toliko spreminjajo - ne zato, ker je strategija spremenljiva (v teoriji to niti ni nujno), temveč zato, ker strategi živijo in razmišljajo v kontekstualno omejenem prostoru in času. Evolucija strategije tako prikazuje dinamično interakcijo med kontekstom in strategi skozi čas.

2. V celotni zgodovini človeka je prevladoval strateški narativ, ne glede na to, kako se je imenoval in kako je bil takrat opredeljen. Še več; čeprav so strategi v preteklosti govorili v grščini, latinščini, francoščini, nemščini ali v katerem koli drugem jeziku, so njihove misli in vedenja bila vselej usmerjena v potrebe takratnega sodobnega zgodovinskega konteksta. Strategija je bila vedno funkcija, katere bistvena logika je v odpornosti na negotovost nekega časa in prostora. Če izhajamo iz te logike, lahko sklenemo, da gre pri strategiji za poskus doseganja želenih političnih ciljev z izbiro primernih strateških načinov, pri čemer se uporabljajo sredstva države, ki so takrat na voljo ali dostopna.

3. Strategija je bolj ali manj stalnica človeških izkušenj. Ta trditev je bistvena za razumevanje večine vidikov tega prispevka. Strategijo delamo, ker nimamo preudarne alternative in ker ta izhaja iz človekovih političnih okoliščin. Zgodovinske izkušnje nam namreč niso omogočile nobene druge preudarne izbire kot te, da se vedemo tako politično kot tudi strateško. Strategije pa pri tem ne smemo enačiti s politiko, čeprav sta oba koncepta, kot pravi Gray, med seboj vzajemno odvisna (Gray, 2016, str. 1). Politika določa strategiji njen namen, strategija pa zagotavlja politiki način, kako se ta namen lahko uresniči v praksi. Če mora potreba po strategiji neizogibno izhajati iz politike, bi morala biti intelektualna posledica ta, da smo zelo dobro pripravljeni na politični kontekst, ki akutno potrebuje strategijo. 
Sklep Za marsikoga je strategija skrivnosten, morda celo, kot pravi Gray, zlovešč pojav (Gray, 2015, str. 25). Jasnejši pomeni strategije so namreč veliko bolj povezani z abstraktno logiko, medtem ko oprijemljivejši pomeni njene vsestranske vloge $\mathrm{v}$ družbi veljajo za nejasne in izmuzljive. To protislovje v razumevanju pomena strategije je precej povezano z zgodovinskimi izkušnjami, ki ustvarjajo številne različne sodbe o naravi vojne in politike, ki jo usmerja, zato lahko povzročijo oziroma spodbudijo močne, v zgodovini večkrat tudi čezmerne strateške imperative. Pri vsem tem ni toliko pomembno, ali je politika oblikovala strategijo ali strateški imperativ, pomemben je kontekst presoje v njih. Napačne presoje v oblikovanju obeh lahko pripeljejo do neuspeha ali katastrofalnih posledic, tudi za države, ki so na strani zmagovite koalicije. Grenak priokus teh napak vojskujočim se stranem ne popravi niti učinkovita mobilizacija nacionalne volje, ljudi, gospodarske moči, nacionalnega bogastva niti mobilizacija tehnološkega znanja. Millett in Murray pravita, da je to zato, ker je pomembneje sprejemati pravilne odločitve na politični in strateški ravni kot pa na operativni in taktični (Millett in Murray, 1988). Napake v operacijah in taktiki je namreč mogoče popraviti, politične in strateške napake pa živijo večno.

V prispevku smo ugotovili dve bistveni spoznanji. Prvo spoznanje se nanaša na to, da nobena strategija ne sme biti statična, temveč se mora odzivati in prilagajati glede na namere nasprotnika. Druga bistvena realnost pa je, da je strategija funkcija spremenljivk, ki so medsebojno povezane (na primer politični cilji nasprotnih strani), zaradi česar je celotna enačba spremenljivk še bolj zapletena. Čeprav lahko $\mathrm{z}$ analiziranjem različnih modelov in kategorij prispevamo k razumevanju teorije in prakse strategij, te ne morejo ponuditi formul za uspešno oblikovanje strategije ali vodenje vojne. $\mathrm{V}$ vojni in strategiji je večina stvari negotova in spremenljiva, pogosto prepletena s človeškimi nagnjenji, vrednotami in prepričanji, kar otežuje objektivnost raziskovanja in merljivost dejavnikov.

V zadnjih dveh desetletjih obstaja, kot navaja tudi Hoffman (2020), veliko dokazov, ki kažejo na to, da se države, tudi velike, kot so ZDA, spoprijemajo s pomanjkanjem konceptualizacije in težavami pri izvajanju nacionalnih strategij. Nekateri celo trdijo, da so države izgubile veščino njenega oblikovanja in razvijanja. Kljub temu močno dvomimo, da bomo konec zgodovine videli prej, preden bo vrednost dobre strategije zasenčena. Strategija je trajna človekova funkcija, močno povezana s človekovo naravo. Snuje se zaradi človekovih potreb, predvsem zaradi varnosti, oblikuje in do neke mere uresničuje pa se v procesu, ki je po naravi vedno političen. V tem smislu bo strategija ohranila svojo vrednost in korist, vse dokler bodo imele varnostne skupnosti interes in dokler se bodo oblikovalci politik in vojaški poveljniki morali spoprijemati z varnostnimi izzivi in pri tem usklajevati sredstva za dosego želenih ciljev. 
1. Anonymous Byzantine, 6. stol. Peri Strategikes, de re strategica. Prevedel George, D. (1985). Three Byzantine Military Treatises. Washington, D.C.: Dumbarton Oaks. https:// www.scribd.com/doc/312006858/Dennis-George-Three-Byzantine-Military-Treatises (14. 5. 2018).

2. Aron, R., 2003. Peace and war: a theory of international relations. London: Transaction.

3. Beaufre, A., 1968. Uvod u strategiju. Beograd: Vojnoizdavački zavod.

4. Betts, R., 2001/02. The Trouble with Strategy. Joint Force Quarterly, Autumn/Winter, 23-30.

5. Brodie, B., 1973. War and Politics. London: Cassell.

6. Clausewitz, C., 2004. O vojni. Ljubljana: Studia Humanitatis.

7. Dictionary of United States Military Terms, 1950. Joint Chiefs of Staff (1st revision). Washington. https://archive.org/details/ DictionaryOfTheUnitedStatesMilitaryTermsForJointUsage (11. 5. 2018).

8. Dolman, C. E., 2016. Seeking Strategy. V R. J. Bailey (jr.), J. W. Forsyth (jr.) in M. O. Yeisley (ur.), Strategy; Context and Adaptation from Archidamus to Airpower (str. 5-37). Annapolis: Naval Institute Press.

9. Foch, F. (prevod Belloc, H.), 1920. The Principles of War. New York: Henry Holt and Company.

10. Förster, S., in Gessler, M., 2005. The Ultimate Horror: Reflections on Total War and Genocide. V R. Chickering, S. Förster in B. Greiner (ur.), A World at Total War: Global Conflict and the Politics of Destruction, 1937-1945 (str. 53-68). Cambridge: Cambridge University Press.

11. Freedman, L., 2013. Strategy: A History. New York: Oxford University Press.

12. Gray, C., 2010. The Strategy Bridge: Theory for Practice. New York: Oxford University Press.

13. Gray, C., 1999. Modern Strategy. Oxford: Oxford University Press.

14. Gray, C., 2016. Strategy and Politics. London: Routledge.

15. Gray, C., 2015. The Future of Strategy. Cambridge: Polity Press.

16. Handel, M., 2003. Masters of War: Classical Strategic Thought. 3. izdaja. London: Frank Class Publishers.

17. Henderson, G. F. R., 1910. The Science of War: A Collection of Essays and Lectures, 1891-1903. London: Longmans, Green and CO.

18. Heuser, B., 2010. The Evolution of Strategy. Thinking War from Antiquity to the Present. Cambridge: Cambridge University Press.

19. Hoffman, F. 2020. Distilling the Essence of Strategy. Media news (10. 8. 2020). Institute for National Strategic Studies, Center for Strategic Research at National Defense University. https://inss.ndu.edu/Media/News/Article/2307863/distilling-the-essence-ofstrategy/ (19. 3. 2021).

20. Hughes, D. (ur.), 1993. Moltke on the Art of War: Selected Writings. San Francisco: Presidio Press.

21. James, H. W., 1908. Modern Strategy: an outline of the principles which guide the conduct of campaigns. Edinburgh in London: William Blackwood and Sons.

22. Jomini, A. H. (prevod Mendell, G. H. in Craighill, W. P.), 2007. The Art of War. Rockville MD: Arc Manor.

23. Kromayer, J., 1925. Waren Hannibal und Friedrich der Grosse Wirklich Ermüdungsstrategen? Historische Zeitschrift, 131 (3), str. 393-408.

24. Lassau, F. C., 1815. Der Krieg: Für wahre Krieger. Lepzig: Engelmann.

25. Leon VI. Modri., 900. Leonis VI. Tactica. Prevedel George, D., 2010. The Taktika of Leo VI.. Washington, D.C.: Dumbarton Oaks. https://www.scribd.com/document/321408134/ Tactica-of-Emperor-Leo-VI-the-Wise (14. 5. 2018). 
26. Liddell Hart, H. B., 1967. Strategy: The Classic Book on Military Strategy. Second Revised Edition. London: Faber\&Faber Ltd.

27. Liddell, G. H., in Scott, R., 1940. Greek-English Lexicon. Oxford: Claredon Press.

28. Lubi, D., 2008. Teorija strategije - študijsko gradivo. Ljubljana: Univerza v Ljubljani, Fakulteta za družbene vede.

29. Marmont, Marshal, duc de Raguse, 1865. Modern Armies. London: W. O. Mitchell, Military Library.

30. Murray, W., in Grimsley, M., 1994. On Strategy. V W. Murray, M. Knox in A. Bernstein (ur.), The Making of Strategy: Rulers, States and War (str. 1-23). New York: Cambridge University Press.

31. Millett, A., in Murray, W., 1988. Lessons of War. The National Interest, JSTOR, vol. 14, str: 83-95.

32. Neild, R., 1990. An Essay on Strategy: as it Affects the Achievement of Peace in a Nuclear Setting. London: The Macmillan Press LTD.

33. Strachan, H., 2006. Making Strategy: Civil-Military Relations after Iraq. Survival, 48 (3), 59-82.

34. Wilkinson, H. S., 1894. Command of the Sea and Brain of the Navy. Westminster in London: Archibald Constable.

35. Willisen, W., 1840. Die Theorie des großen Krieges. Berlin: Duncker und Humblot.

36. Žabkar, A., 2003. Marsova dediščina, temelji vojaških ved (1. knjiga). Ljubljana: Fakulteta za družbene vede. 